\title{
A Brother and Sister with the Same Karyotype: Case Report of Two Siblings with Partial 3p Duplication and Partial 9p Deletion and Sex Reversal
}

\author{
Susan Cordes Selby ${ }^{1}$, Aiko Iwata-Otsubo ${ }^{2}$, Paula Delk ${ }^{2}$, Todd Nebesio ${ }^{2}$, Anisha Gohil ${ }^{2}$, \\ Wilfredo Martinez ${ }^{2}$, Peggy Matlock ${ }^{2}$, and Gail Vance ${ }^{2}$ \\ ${ }^{1}$ Community Hospitals of Indianapolis \\ ${ }^{2}$ Indiana University School of Medicine
}

January 25, 2021

\begin{abstract}
Duplications of $3 p$ and deletions of $9 p$ occurring separately are well described; however, there are few reports of individuals with unbalanced translocations resulting in both of these chromosomal abnormalities. We report two siblings with the same unbalanced male karyotype and sex reversal.

A Brother and Sister with the Same Karyotype: Case Report of Two Siblings with Partial 3p Duplication and Partial 9p Deletion and Sex Reversal

Susan Cordes Selby ${ }^{1}$, Aiko Iwata-Otsubo ${ }^{2}$, Paula Delk ${ }^{2}$, Todd D. Nebesio ${ }^{3}$, Anisha Gohil ${ }^{3}$, Peggy Matlock $^{2}$, Wilfredo Torres-Martinez ${ }^{2}$, Gail H. Vance ${ }^{2}$

${ }^{1}$ Community Health Network, Maternal-Fetal Medicine, Indianapolis, IN

${ }^{2}$ Department of Medical and Molecular Genetics, Indiana University School of Medicine, Indianapolis, IN

${ }^{3}$ Division of Pediatric Endocrinology/Diabetology, Department of Pediatrics, Indiana University School of Medicine, Indianapolis, IN

Running Title: Siblings with 46,XY,der(9)t(3;9)(p25.1;p24.3)

Correspondence to: Gail H. Vance, Department of Medical and Molecular Genetics, Indiana University School of Medicine, 975 W Walnut Street IB-350, Indianapolis, IN 46202-5251. Phone: 317-278-0172. Fax: 317-278-1616. Email: ghvance@iu.edu

\section{ABSTRACT}

Duplications of $3 p$ and deletions of $9 p$ occurring separately are well described; however, there are few reports of individuals with unbalanced translocations resulting in both of these chromosomal abnormalities together. Here we report two siblings with the same unbalanced male karyotype, with a duplication of distal 3p and a deletion of distal 9p, due to adjacent segregation of a balanced reciprocal translocation inherited from their father. Although the siblings have the same karyotype of 46,XY,der(9)t(3;9)(p25.1;p24.3)pat, they demonstrate different phenotypes, particularly in sex development. This sibling pair further delineates cases with unbalanced translocations and disorders of sex development.
\end{abstract}

\section{KEY WORDS}

3p duplication; 9p deletion; disorders of sex development; DMRT1 


\section{KEY CLINICAL MESSAGE}

Two siblings with the same male unbalanced karyotype with sex reversal in the female.

\section{INTRODUCTION}

There have been few patients reported with both partial duplication of $3 p$ and partial deletion of 9p due to an unbalanced translocation with variable breakpoints (Figure S1) (Fryns et al., 1986; Õunap et al., 2004; Witters et al., 2004). Two prior reports of individuals with similar unbalanced translocations to the patients in this report, suggested that the clinical features overlap with those of individuals with isolated 3p duplications and $9 \mathrm{p}$ deletions; however, they are generally milder than expected for the degree of imbalance (Game et al.,1990; McClure et al., 1996) .

Patients with 3p duplications have variable clinical features that include intellectual disability, hypotonia, short stature, heart defects and facial features such as brachycephaly, microcephaly, square face, hypertelorism, wide and depressed nasal bridge, short nose, full cheeks, and cleft lip with and without cleft palate. (Bittel et al., 2006; Natera-de Benito et al., 2014; Smeets et al., 2001).

Clinical features of the 9p deletion syndrome, (OMIM \#158170), include developmental and psychomotor delay, hypotonia, widely spaced nipples, and dysmorphic facial features, such as midface hypoplasia, short palpebral fissures, hypertelorism, depressed nasal bridge and micrognathia (Alfi et al., 1973; Hauge et al., 2008; Huret et al., 1988; Swinkels et al., 2008). A significant number of patients with a distal 9p deletion with a male karyotype exhibit disorders of sex development (DSD) (Barbaro et al., 2009; Ônap et al., 2004).

Here, we report a brother and sister with the same male karyotype with an unbalanced translocation resulting in partial duplication of $3 \mathrm{p}$ and distal deletion of $9 \mathrm{p}$. Both patients' clinical features include those seen in $3 p$ duplication and 9p deletion, including abnormal sex development.

\section{CLINICAL REPORTS}

\section{Patient 1}

Patient 1 was born at 38 weeks gestation by repeat Cesarean section to a 33-year-old G2P1001 mother. Prenatal ultrasound detected a Dandy-Walker malformation, confirmed after birth with brain MRI. The remainder of the pregnancy was unremarkable. The family history was remarkable for a sister (patient 2) with an atrial septal defect (ASD) and clubfeet. The remainder of the family history was negative for birth defects, intellectual disability, and recurrent miscarriages. The mother and father are second cousins (their mothers are first cousins).

The patient's birth weight was $3.78 \mathrm{~kg}\left(69^{\text {th }}\right.$ percentile), length was $54.0 \mathrm{~cm}$ ( $93^{\text {rd }}$ percentile), and Apgar scores were 8 and 9 at 1 and 5 minutes, respectively. He had neonatal hypoglycemia, which resolved spontaneously within the first day of life, and feeding difficulties, which resolved by 6 months of age. A patent foramen ovale was identified.

At birth, the patient had ambiguous genitalia with a bifid scrotum. Specifically, he had a penoscrotal transposition with buried penis and prominent suprapubic fat pad. He also had ventral chordee, left-sided hydrocele, and a left inguinal hernia. The patient had a low luteinizing hormone (LH) and lower limits of normal folliclestimulating hormone (FSH) in the newborn period. Testosterone and dihydrotestosterone levels were normal for age, but anti-Mullerian hormone was low for newborn males, suggesting normal Leydig cell function but abnormal Sertoli cell function. A renal ultrasound showed normal appearing kidneys bilaterally with no evidence of hydronephrosis. At 7 months of age, the patient had a penoplasty, scrotoplasty and repair of the left inguinal hernia and hydrocele.

The patient had both developmental and speech delay, He sat alone at approximately 5 months, crawled at 11 months, and was not walking independently at 16 months of age. Growth parameters at 16 months of age were $11.4 \mathrm{~kg}$ ( $53^{\text {rd }}$ percentile) for weight, $78.6 \mathrm{~cm}\left(29^{\text {th }}\right.$ percentile) for length, and an OFC of $49 \mathrm{~cm}$ $\left(87^{\text {th }}\right.$ percentile). Mildly dysmorphic features observed included short palpebral fissures with hypertelorism, 
cupped ears with overfolded helices, short nose, a smooth philtrum, full cheeks, and micrognathia. (Figure 1a). Other features noted were displaced nipples, tapered fingers, edema of the feet, and loose skin.

At age 9 years, he underwent an adenoidectomy and turbinate cauterization due to concerns for apnea. His growth parameters for height, weight and head circumference were at the $75^{\text {th }}-90^{\text {th }}$ percentile. He had moderate expressive and receptive language delays and received speech intervention, occupational, music, physical, and recreational therapies. He was diagnosed with ADHD, and is homeschooled, working at a 3rd grade level. At age 10 years 11 months, he is prepubescent. A testicular ultrasound revealed healthy appearing bilateral testes located within the scrotum without mass or concerning features. His gender identity remains male.

G-banded chromosome analysis, performed at birth, identified additional unknown material on 9p. Parental blood studies demonstrated that the patient's father had a balanced reciprocal translocation between 3p and $9 \mathrm{p}$ written as $46, \mathrm{XY}, \mathrm{t}(3 ; 9)(\mathrm{p} 25.1 ; \mathrm{p} 24.3)$. Based on paternal results, the patient's karyotype was revised to 46,XY,der(9)t(3;9)(p25.1;p24.3)pat, resulting in partial 3p duplication and partial 9p deletion.

Chromosomal microarray analysis (CMA) identified a duplication at 3p26.3p25.1, approximately $13.5 \mathrm{Mb}$ in size involving 55 OMIM genes (chr3:61,891-13,562,132, hg19 coordinates) and a deletion at 9p24.3, approximately $1.17 \mathrm{Mb}$ in size involving 5 OMIM genes (chr9:203,861-1,373,611, hg19 coordinates). Also identified were segments of copy-neutral absence of heterozygosity $(\mathrm{AOH})$ across multiple chromosomes encompassing around $2.2 \%$ of the genome (Figure S2).

\section{Patient 2}

Patient 2 (sister to patient 1) was born at term by Cesarean section due to large size and posterior positioning. The pregnancy was without complications. Birth weight was $3.94 \mathrm{~kg}\left(87^{\text {th }}\right.$ percentile) and birth length was $48.9 \mathrm{~cm}$ ( $43^{\text {rd }}$ percentile). Hypoglycemia developed shortly after birth, which resolved spontaneously. She had bilateral talipes equinovarus and a moderate-sized ASD noted by echocardiogram.

A chromosome study of Patient 2 demonstrated the same karyotype as her brother, 46,XY,der(9)t(3;9)(p25.1;p24.3)pat. However, she had normal-appearing female external genitalia. A renal ultrasound was normal, and a pelvic ultrasound initially appeared normal with both ovaries and a uterus present. Gonadotropins measured at 2 years 8 months demonstrated her LH was normal but FSH was markedly elevated, suggesting gonadal dysgenesis and primary ovarian dysfunction. Laparoscopy showed a normal uterus and Fallopian tubes. The ovaries appeared normal except for a right cystic structure. The patient had a bilateral gonadectomy. Pathology reports of the left gonad revealed a streak testis containing a gonadoblastoma while the right gonad was an ovotestis.

The patient had developmental delays, especially with gross motor and language skills. She walked at 20 months and said her first words at 18 months. At 3 years 2 months, her vocabulary consisted of reportedly more than 100 single words and she was able to use two-word phrases.

The patient's growth parameters at 3 years 5 months of age were $15.4 \mathrm{~kg}$ ( $64^{\text {th }}$ centile) for weight, 98 $\mathrm{cm}\left(56^{\text {th }}\right.$ centile) for height, and she had an OFC of $51.2 \mathrm{~cm}\left(80^{\text {th }}\right.$ centile). At age 11 years, her growth parameters were at $75^{\text {th }}-90^{\text {th }}$ percentiles for height, weight and head circumference. Dysmorphic features included brachycephaly, broad forehead, short nasal bridge, and hypoplastic ala nasi. Percutaneous closure of her ASD was performed and she has remained asymptomatic. On endocrine evaluation at age 11 year 7 months, her breasts were at Tanner stage I and pubic hair was Tanner stage III. She began treatment for hypergonadotropic hypogonadism with an estradiol patch at $12.5 \mathrm{mcg}$ twice weekly. Her bone age was concordant with her chronological age of between 10 and 11 years. An exam at age 13 years 8 months, noted Tanner stage III breasts and Tanner stage IV pubic hair. She has not yet had menarche. Her gender identity remains female.

Developmentally, the patient was functioning with moderate cognitive delays and severe language delay. She was receiving speech, occupational, and recreational therapies. She has been homeschooled and is performing near the $4^{\text {th }}$ grade level. 
Similarly, a CMA showed a duplication at 3p26.3p25.1, approximately $13.46 \mathrm{Mb}$ in size involving 55 OMIM genes (chr3:61,891-13,562,132, hg19 coordinates) and a deletion at 9p24.3, approximately $1.17 \mathrm{Mb}$ in size involving 5 OMIM genes (chr9:203,861-1,373,611, hg19 coordinates; Figure 1c). The microarray also identified segments of copy-neutral AOH across multiple chromosomes encompassing around $3.8 \%$ of the genome (Figure S2).

\section{MATERIALS AND METHODS}

High-resolution chromosome analysis was performed on 20 metaphases on PHA-stimulated cultured lymphocytes using the standard GTG (G-banding using trypsin and Giemsa) banding protocol. CMA analysis was performed on genomic DNA extracted from peripheral blood using the Applied Biosystems CytoScan HD array platform (ThermoFisher Scientific, Carlsbad, CA) consisting of 1,953,246 unique non-polymorphic copy-number probes and 743,304 single nucleotide polymorphism probes spanning the whole genome. CytoScan array CEL files were processed and visualized with the Chromosome Analysis Suite (ChAS) 3.3 version software (ThermoFisher Scientific, Carlsbad, CA) The copy number variants (CNVs) were analyzed and reported using the NCBI human genome build 37.1 (GRCh37/hg19).

\section{DISCUSSION}

In this report, we present phenotypically male and female siblings each with the same male karyotype with partial 3p duplication and partial 9p deletion. Their clinical features overlap those associated with 3p duplication and $9 \mathrm{p}$ deletion (Table S1). The duplicated $3 \mathrm{p}$ and deleted $9 \mathrm{p}$ regions are smaller in our patients compared to the common sizes associated with patients reported in the literature, which could account for the milder phenotype in our patients.

The 9p deletion syndrome is associated with DSD. Patients with a distal 9p deletion and a male karyotype, show a wide spectrum of abnormal sex development ranging from females with complete gonadal dysgenesis to males with hypospadias. The critical region for complete gonadal dysgenesis has been localized to the 9p24.3, extending from the DMRT genes to the telomere (Barbaro et al., 2009; Guioli et al., 1998; Veitia et al., 1997) This region is separate from the 9p deletion syndrome critical region (9p22.3-9p23) (Flejter et al., 1998; Veitia et al., 1997). The DMRT genes (DMRT1 , DMRT2 , andDMRT3 ) located at 9p24.3 are considered as gene candidates for gonadal dysgenesis (Muroya et al., 2000). These genes encode for proteins with a DM (doublesex/MAB-3) domain, a zinc-finger-like DNA binding, and are involved in downstream pathways of sex determination (Barbaro et al., 2009). In mice, Dmrt1 is expressed in both germ cells and Sertoli cells of the testis, and has been shown to be essential to maintain testis determination (Raymond, 2000). Recent studies in humans support that haploinsufficiency of DMRT1, associated with 9p deletions, is the most likely explanation of DSD. Macdonald et al. (2018) used a novel approach to repress DMRT1 in the tissue of human fetal testes, and showed DMRT1 repression induces testicular dysgenesis. Furthermore, a recent exome study identified a missense mutation in DMRT1 in a patient with XY sex reversal (Murphy et al., 2015) further supporting that DMRT1 is a candidate gene for XY sex reversal.

It has been shown that haploinsufficiency for DMRT1 results in gonadal dysgenesis and DSD with variable penetrance and expressivity (Quinonez et al., 2013). A review of 88 cases of monosomy 9p with a male karyotype revealed that $\sim 80 \%(72 / 88)$ had genital abnormalities and/or complete gonadal dysgenesis, while $\sim 20 \%$ of them had no genital abnormalities. The underlying mechanism of this variability has been unclear. Since a large percentage of $46, \mathrm{XY}$ patients with $9 \mathrm{p}$ deletions that had DSD harbored a secondary copy number variation $(\mathrm{CNV})$, the authors hypothesized that abnormal sex development may be due to the presence of a second-hit (CNV or other molecular mechanism) in addition to DMRT1 haploinsufficiency. In our study, we did not detect significant $\mathrm{CNVs}$ however, regions of $\mathrm{AOH}$ were detected with the regions of $\mathrm{AOH}$ in patient 2 being larger (3.78\% of the entire genome including $62 \mathrm{Mb} \mathrm{AOH}$ on chromosome 7 ) than in patient 1 (2.22\% of the entire genome; Figure S2). It may be possible that a homozygous state of a gene or genes in the $\mathrm{AOH}$ regions in patient 2 served as a second hit, accounting for her sex reversal phenotype. Alternatively, it may be possible that additional small CNVs or other genetic changes undetectable by CMA account for the difference in sex development between the two patients. 
In conclusion, the two patients reported here add to the study of individuals with partial 3p duplication and 9p deletion. Of reported cases, only two have had 46,XY and sex reversal (Fryns et al., 1986; Witters et al., 2004). Our two patients are also of interest as they are a brother and sister with the same genotype defined by karyotype and CMA, but their phenotypes, specifically in regards to sex development and gender identity, are different.

\section{ACKNOWLEDGEMENTS}

We thank the family for their cooperation with this study.

\section{DATA AVAILABILITY}

The data that support the findings of this study are available from the corresponding author upon reasonable request.

\section{AUTHOR CONTRIBUTIONS}

Clinical Evaluation SCS, PD, TDN, AG, WTM; Data Analysis AIO, PM, GHV; SCS, AIO and GHV prepared the manuscript; all authors reviewed and contributed to the drafts and approved the final manuscript.

\section{REFERENCES}

Alfi, O., Donnell, G. N., Crandall, B. F., Derencsenyi, A., \& Menon, R. (1973). Deletion of the short arm of chromosome \# 9 (46,9p-). A new deletion syndrome. Annales de Genetique , 16 (1), 17-22.

Barbaro, M., Balsamo, A., Anderlid, B. M., Myhre, A. G., Gennari, M., Nicoletti, A., Pittalis, M. C., Oscarson, M., \& Wedell, A. (2009). Characterization of deletions at 9p affecting the candidate regions for sex reversal and deletion 9p syndrome by MLPA Sweden. European Journal of Human Genetics , 17 (11), $1439-1447$.

Bittel, D. C., Kibiryeva, N., Dasouki, M., Knoll, J. H. M., \& Butler, M. G. (2006). A 9-year-old male with a duplication of chromosome 3p25.3p26.2: Clinical report and gene expression analysis.American Journal of Medical Genetics , 140 A (6), 573-579.

Flejter, W. L., Fergestad, J., Gorski, J., Varvill, T., \& Chandrasekharappa, S. (1998). A Gene Involved in XY Sex Reversal Is Located on Chromosome 9, Distal to Marker D9S1779. The American Journal of Human Genetics , 63 (3), 794-802.

Fryns, J. P., Kleczkowska, A., Casaer, P., \& Van Den Berghe, H. (1986). Double autosomal chromosomal aberration (3p trisomy/9p monosomy) and sex reversal. Annales de Genetique, 29 (1), 49-52.

Game, K., Friedman, J. M., \& Kalousek, D. K. (1990). Mild phenotypic abnormalities in combined del 9p2 and dup 3p2. American Journal of Medical Genetics , 35 (3), 370-372.

Guioli, S., Schmitt, K., Critcher, R., Bouzyk, M., Spurr, N. K., Ogata, T., Hoo, J. J., Pinsky, L., Gimelli, G., Pasztor, L., \& Goodfellow, P. N. (1998). Molecular Analysis of 9p Deletions Associated with XY Sex Reversal: Refining the Localization of a Sex-Determining Gene to the Tip of the Chromosome. The American Journal of Human Genetics ,63 (3), 905-908.

Hauge, X., Raca, G., Cooper, S., May, K., Spiro, R., Adam, M., \& Martin, C. L. (2008). Detailed characterization of, and clinical correlations in, 10 patients with distal deletions of chromosome 9p.Genetics in Medicine , 10 (8), 599-611.

Huret, J. L., Leonard, C., Forestier, B., Rethore, M. O., \& Lejeune, J. (1988). Eleven new cases of del(9p) and features from 80 cases. InJournal of Medical Genetics (Vol. 25, Issue 11, pp. 741-749). BMJ Publishing Group.

Macdonald, J., Kilcoyne, K. R., Sharpe, R. M., Kavanagh, Á., Anderson, R. A., Brown, P., Smith, L. B., Jørgensen, A., \& Mitchell, R. T. (2018). DMRT1 repression using a novel approach to genetic manipulation induces testicular dysgenesis in human fetal gonads. Human Reproduction , 33 (11), 2107-2121. 
McClure, R. J., Telford, N., \& Newell, S. J. (1996). A mild phenotype associated with der(9)t(3;9) (p25;p23). Journal of Medical Genetics , 33 (7), 625-627.

Muroya K, Okuyama T, Goishi K, Ogiso Y, Fukuda S, Kameyama J, Sato H, Suzuki Y, Terasaki H, Gomyo H, Wakui K, Fukushima Y, Ogata T. 2000. Sex-Determining Gene(s) on Distal 9p: Clinical and Molecular Studies in Six Cases ${ }^{1}$. J. Clin. Endocrinol. Metab. 85: 3094-3100.

Murphy MW, Lee JK, Rojo S, Gearhart MD, Kurahashi K, Banerjee S, Loeuille G-A, Bashamboo A, McElreavey K, Zarkower D, Aihara H, Bardwell VJ. 2015. An ancient protein-DNA interaction underlying metazoan sex determination. Nat. Struct. Mol. Biol. 22: 442-451.

Natera-de Benito, D., García-Pérez, M. A., Martínez-Granero, M. Á., \& Izquierdo-López, L. (2014). A patient with a duplication of chromosome 3p (p24.1p26.2): A comparison with other partial 3p trisomies.American Journal of Medical Genetics, Part A , 164 (2), 548-550.

Õunap, K., Uibo, O., Zordania, R., Kiho, L., Ilus, T., Õiglane-Shlik, E., \& Bartsch, O. (2004). Three patients with 9p deletions including DMRT1 and DMRT2: A girl with XY complement, bilateral ovotestes, and extreme growth retardation, and two XX females with normal pubertal development. American Journal of Medical Genetics , 130 A (4), 415-423.

Quinonez, S. C., Park, J. M., Rabah, R., Owens, K. M., Yashar, B. M., Glover, T. W., \& Keegan, C. E. (2013). 9p partial monosomy and disorders of sex development: Review and postulation of a pathogenetic mechanism. American Journal of Medical Genetics Part A ,161 (8), 1882-1896.

Raymond CS. 2000. Dmrt1, a gene related to worm and fly sexual regulators, is required for mammalian testis differentiation. Genes Dev. 14: 2587-2595.

Smeets, E., Vandenbossche, L., \& Fryns, J. P. (2001). Partial distal trisomy 3p. A partial autosomal trisomy without major dysmorphic features. Genetic Counseling , 12 (1), 85-89.

Swinkels, M. E. M., Simons, A., Smeets, D. F., Vissers, L. E., Veltman, J. A., Pfundt, R., de Vries, B. B. A., Faas, B. H. W., Schrander-Stumpel, C. T. R. M., McCann, E., Sweeney, E., May, P., Draaisma, J. M., Knoers, N. V., van Kessel, A. G., \& van Ravenswaaij-Arts, C. M. A. (2008). Clinical and cytogenetic characterization of 13 Dutch patients with deletion 9p syndrome: Delineation of the critical region for a consensus phenotype.American Journal of Medical Genetics Part A , 146A (11), 1430-1438.

Veitia, R., Nunes, M., Brauner, R., Doco-Fenzy, M., Joanny-Flinois, O., Jaubert, F., Lortat-Jacob, S., Fellous, M., \& McElreavey, K. (1997). Deletions of distal 9p associated with 46,XY male to female sex reversal: definition of the breakpoints at 9p23.3-p24.1.Genomics , 41 (2), 271-274.

Witters, I., Vermeesch, J. R., Moerman, P. H., \& Fryns, J. P. (2004). Partial trisomy 3p/monosomy 9p with sex reversal. In Ultrasound in Obstetrics and Gynecology (Vol. 23, Issue 4, pp. 418-419).

\section{FIGURE LEGENDS}

Figure 1 - Pictures and CMA results of the two patients

Frontal and lateral views of the patient 1 at the age of 9 months showing a square face, hypertelorism, short palpebral fissures, short nose, full cheeks, cupped ears, smooth philtrum, and micrognathia. (b) Frontal and lateral views of the patient 2 at the age of 2 years 10 months showing hypertelorism, epicanthal folds, smooth philtrum, and depressed nasal bridge. (c) CMA results of patient 1 and patient 2. Both patients have the same deletion on chromosome 9p and duplication on chromosome 3p. Patient 2 has additional $85 \mathrm{~kb}$ - and $42 \mathrm{~kb}$-deletions with no genes present in these regions. These CNVs are considered insignificant.

Figure S1 -Schematic representation of 3p duplications (a) and 9p deletions (b) in this study and previous reported cases.

Figure S2 -AOH regions in patient 1 and patient 2 detected by CMA analysis are shown as purple box. Patient 2 has larger AOH region (3.78\% of the entire genome) than patient 1 (2.22\% of the entire genome), 
including $62 \mathrm{Mb} \mathrm{AOH}$ region on chromosome 7.

\section{A Brother and Sister with the Same Karyotype: Case Report of Two Siblings with Partial 3p Duplication and Partial 9p Deletion and Sex Reversal}

Susan Cordes Selby ${ }^{1}$, Aiko Iwata-Otsubo ${ }^{2}$, Paula Delk ${ }^{2}$, Todd D. Nebesio ${ }^{3}$, Anisha Gohil ${ }^{3}$, Peggy Matlock ${ }^{2}$, Wilfredo Torres-Martinez ${ }^{2}$, Gail H. Vance ${ }^{2}$

${ }^{1}$ Community Health Network, Maternal-Fetal Medicine, Indianapolis, IN

${ }^{2}$ Department of Medical and Molecular Genetics, Indiana University School of Medicine, Indianapolis, IN

${ }^{3}$ Division of Pediatric Endocrinology/Diabetology, Department of Pediatrics, Indiana University School of Medicine, Indianapolis, IN

Gail H. Vance, Department of Medical and Molecular Genetics, Indiana University School of Medicine, 975 W Walnut Street IB-350, Indianapolis, IN 46202-5251. Phone: 317-278-0172. Fax: 317-278-1616. Email: ghvance@iu.edu

(a)
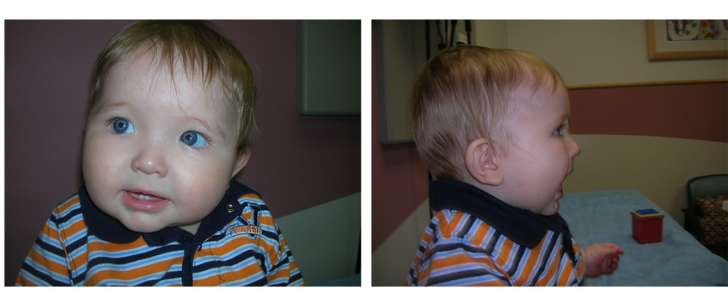

(b)
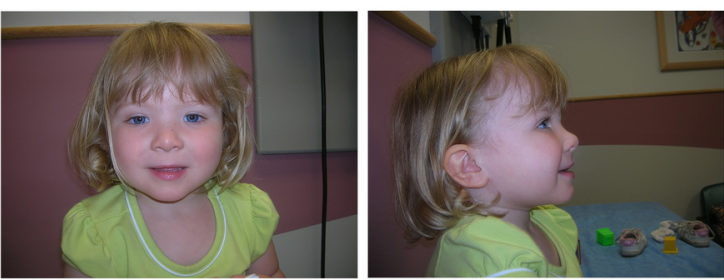

(c) Patient 1

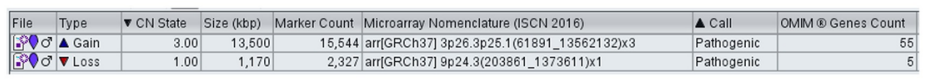

Patient 2

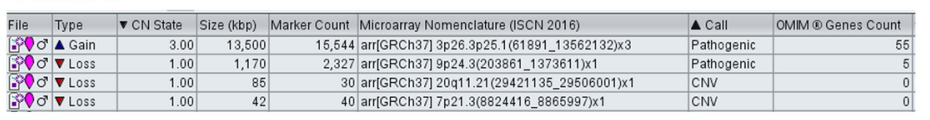

Figure 1 